\title{
Üç Boyutlu Kinetik Tipografi
}

\section{Özet}

Tipografinin çoğu zaman birincil amacı olan okutmaktan çıkarak görsel öge olarak kullanım günümüzde oldukça yaygındır. Bunun yanı sıra teknolojideki gelişmelerin etkileri tipografik çalışmalara da yansımışıtı. Yeni yazılımlar (3B programlar ve hareketlendirme programları vb.), çeşitli ortamlar (dizüstü bilgisayarlar, tabletler, akıllı telefonlar, akıllı televizyonlar vb.) ve deneysel çalışmalar sayesinde daha etkili ifade biçimleri yaratabilmektedir. Tipografinin hareketlendirilmesi ile yaratıcı görsellikler ve yenilikçi çalıșmalar üretilir hale gelmiștir. Bu kullanım tarzı etkileyici tasarımlar yaratıcı görsellikler ve yenilikçi çalışmalar üretilir hale gelmiştir. Bu kullanım tarzı etkileyici tasarımlar ortaya çıkarmakta önemli bir güce sahiptir. Gelinen bu teknolojik aşamada yaygınlaşmaya başlayan
üç boyutlu kinetik tipografi uygulamalarının bir çoklu ortam ürünü olarak nasıl tasarlandığının ve üretildiğinin incelenmesi günün ve geleceğin iletişim beklentilerini karşılamaya yönelik bir çaba için gereklidir. Bu çalıșmada üç boyutlu kinetik tipografi'nin kullanım alanları ve önemli örnekler incelenmiş, elde edilen veriler ve çıkarımlar ışığında yeni ifade biçimlerinin etkileri ortaya konulmuştur.

Anahtar Sözcükler: Üç Boyut, Kinetik Tipografi, Hareket, Grafik Tasarım, Sinema

\section{THREE DIMENSIONAL KINETIC TYPOGRAPHY}

\section{Abstract}

The various uses of typography are quite common today. Typography is often used as a visual element, out of the primary purpose of reading. The effects of the developments in technology were reflected in typographic studies, new and effective expression forms could be created with new software in typographic studies, new and effective expression forms could be created with new software
enviroments (3D programs and animation programs etc.), new media (laptop computers, tablets, smartphones, smart TVs etc) and new experimental works. With moving of typography, creative visualizations and innovative designs have become producible. This usage of style has a considerable strength in revealing impressive design. In today's technological stage for an effort to meet with the communication expectations of the day and future, examination of how the three-dimensional kinetic typography studies, that have become widespread has been designed and produced as a multimedia product, is necessary. In this study, the application areas and important examples of three-dimensional kinetic typography are examined, in the light of the obtained data and inferences the effects of new expression ways are presented.

Keywords: Three Dimension, Kinetic Typography, Motion, Graphic Design, Cinema. 


\section{Giriş}

Endüstri devrimi ile gelişen basım teknolojisi, tipografinin gelişimi için uygun ortamı hazırlamıştır. Gelişen araçlarla genişleyen tipografi kavramı sadece bir tekniği anlatmanın ötesine geçmiştir. Bununla birlikte modern dönemin sanat akımlarının (fütürizm, dadaizm, konstrüktivizm, v.d.) katkısı ile tipografinin çeşitli kullanımları ortaya çıkmışır. Tipografi sadece bilginin görselleştirilerek okunması ve okutulmasının dışında biçimsel bir gösterge olmuştur. Kullanılan karakterler düşunce ve fikirleri ifade etmenin bir yolu olarak kullanılmıştır. Tipografi, işlev ve estetikten fazlasını ifade etmekte ve içerik ile bağlantı kurması sağlanmaktadır. Yazılar sadece yazı değil aynı zamanda içeriğin bir taşıyıcısı konumuna gelmektedir.

Bilgisayar keşfedilmeden çok önce 20. yüzyıl'ın ilk çeyreğinde, tipografideki gelişim ve değişimler sayesinde yeni bir terim oraya çıkmışır. Bu terim yani kavramsal tipografi için kinetik tipografinin temelini oluşturduğunu söylemek yanlış olmayacaktır.

íki boyutlu durağan iletinin bir adım ötesinde, kaydedilebilir sürekli görüntü ortamı olarak adlandırılan video teknolojisiyle birlikte zaman boyutu da iletime bir tasarım ögesi olarak eklenmiş ve akar görüntü, ses, ses-görüntü-hareket eşleştirmesi (sychronization), video grafikleri, hareket eden tipografi, video ve sinema efektleri gibi olgular hareketli grafikler (motion graphics) üst başlığının altında yer almaya başlamışır.

Masaüstü yayıncılık ve sonrasında geliştirilen bilişim teknolojileri aracılığıyla tipografi yükselen bir değere sahip olur. Bu süreçte insanoğlunun metinsel bilgiyi tüketimi farklılaşır. Basılı sayfanın ekran ve cihaz görüntüleme ortamına genişletilmesi, yazının olasılıklarını artırmış ve yazıyı hareketli hale getirmiştir. "Hareket eden yazı (moving type), yeni teknolojilerin kullanımıyla ortaya çıkan, yazının yeni niteliklerine bir örnektir" (Bachfischer, Robertson ve Zmijewska, 2007: 1).

Yeni bir konu olan üç boyutlu kinetik tipografi üzerine hareketli grafik (motion graphics) kitapları içinde yer alan küçük bölümler dışında bir çalışma bulunmamaktadır. Bu durum, alanda çalışma yapılması gerekliliğini gözler önüne sermektedir.

Yaygınlaşmaya başlayan üç boyutlu kinetik tipografi uygulamalarının üç boyutlu bir çoklu ortam ürünü olarak nasıl tasarlandığının ve üretildiğinin incelenmesi, günün ve geleceğin iletişim beklentilerini görsel tasarımlarla karşılamaya yönelik bir çaba için gereklidir.

\section{Üç Boyutlu Kinetik Tipografi}

Kinetik tipografi bilgisayar kullanılarak üretilen karakter animasyonudur. Hareketli karakterler kendi dilindeki duygu ve sesi vurgular. Bununla birlikte her hareketli yazı kinetik tipografi anlamına gelmez. Duygu, anlam ve kavram katılmamış hareketli yazı, kinetik tipografi anlamına gelmemektedir. Hareketli tipografide, -videolarda kullanılan alt yazılarda olduğu gibi- bilgi sadece yazının okunması ile izleyiciye sunulurken, kinetik tipografide ise bilgi; yazının okunmasının yanı sıra harflerin ve kelimelerin aynı zamanda kavramları, hareketleri, sesleri ve durumları ifade etmesi ile sunulmaktadır (Görsel 1, 2).

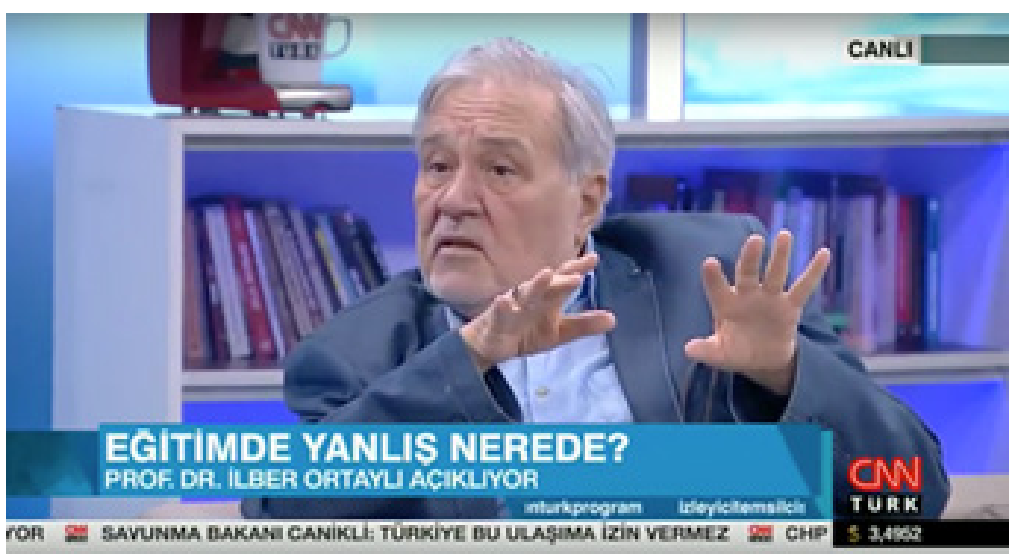

Görsel I. Hareketli Tipografi'ye bir örnek, 2017, Video

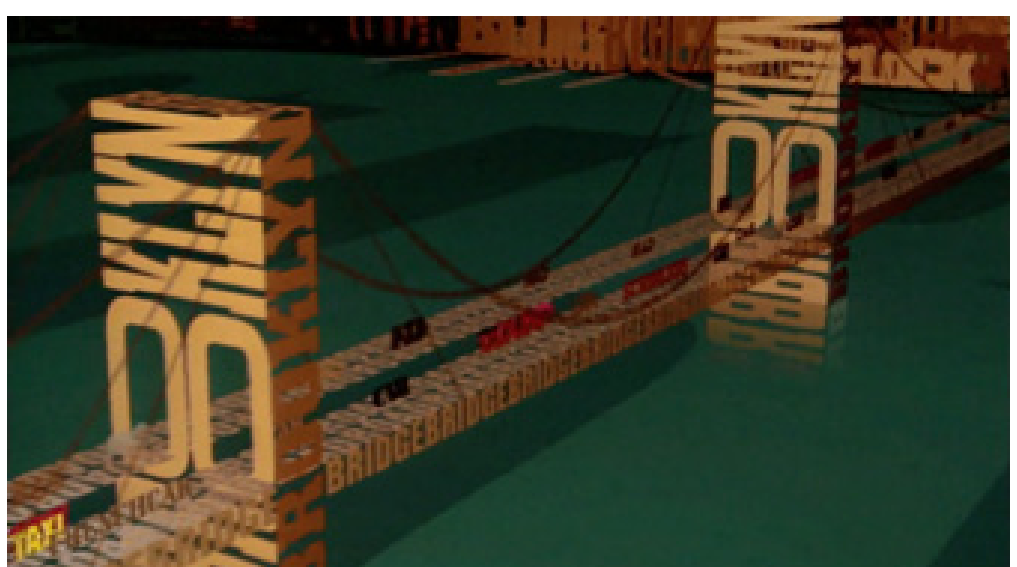

Görsel 2. Alex Gopher, The Child Kinetik Tipografi'ye bir örnek, Saul Bass, Anatomy of a Murder filmi açılış jeneriği, 1959, Video 2007, Video 
Kerry Bodine ve Mathilde Pignol'a göre; "Zaman içerisinde görüntüsü değişen metin anlamına gelen kinetik tipografi, metine duygusal içerik eklenmesiyle yeni bir ifade biçimidir." (Bodine ve Pignol, 2003: 914).

Sarıkavak'a (2013) göre; kinetik tipografi, modern dönemin kavramsal tipografisinin bilgisayar ve yeni medyada geliştirilmiş biçimidir. 20. yy'ın ve postmodernizmin iki boyutlu yüzeylerde sanal üç boyutlu tasarımların teknoloji sayesinde, ses ve zaman boyutlarının da eklenmesiyle, aslında en az beş boyutlu tipografi uygulamalarıdır. Altıncı boyutun ise duygulanım (duygusal etkileşim) olduğunu söylemek mümkündür.

\section{Kullanım Alanları}

Üst bașlık olarak hareketli grafikler (motion graphics) alt basslık olarak kinetik tipografinin içerisinde yer alan "üç boyutlu kinetik tipografi" yeni bir kavram olmasına karşın çeșitli alanlarda ve ortamlarda (medium) yerin almıştır. Bu alanların gün geçtikçe genişleyeceği olası bir durumdur. Üç boyutlu tipografi kullanım alanları, sinema, televizyon ve sayısal ortam olmak üzere üç ana başlık altında incelenebilir.

\section{Sinema}

Üç boyutlu kinetik tipografi kullanımına sinemada; film jeneriklerinde, reklamlarda ve filmlerde rastlanmaktadır. Film jenerikleri, tipografinin ve görselin hareketle buluştuğu önemli deneysel alanlardan biridir. "Film jeneriklerinin tasarım amacı filmin bilgilendirici metnini izleyiciye aktarmak olduğu için, kinetik tipografinin en yenilikçi ve etkileyici örnekleri bu alanda karşımıza çıkmaktadır" (Kılıç, 2011: 33).

Film jeneriklerinde kinetik tipografi kullanımına ilk kez Saul Bass'ın tasarımlarında rastlanılmaktadır. Alfred Hitchcock, Martin Scorcese, Stanley Kubrick ve Otto Preminger gibi yönetmenlerle yaptığı çalışmalarla dikkat çeken Saul Bass çalışmalarını şöyle açıklamaktadır:

Ortalama bir sinema izleyicisi için, filmin girişindeki krediler bölümü patlamış mısırlarını bitirmek için sadece üç dakikaları kaldı ğının göstergesidir. Ben bu ölü zamanı, film izleyicisinin ilgilenmediği isim listesini sunarak bu işten kurtulmanın ötesinde birşeyler için değerlendirmek istedim. İzleyiciyi izlemek üzere olduklan filme hazıllamak ve beklenti sahibi olmalarını sağlamayı hedefledim ("Bass on Titles", 2006).

1950'lerde Saul Bass film jeneriklerinde devrimler gerçekleștirir. Film ve televizyon yayıncılık endüstrisi geleneksel grafik tasarım dili ile dinamik görsel sinemanın dilini bütünleştirir (Krasner, 2008: 29).
Bass'ın yeteneği, filmin görsel dilini çözmesinden kaynaklanmaktadır. Hareketli kompozisyonları, müzikle de eşleşerek adeta filmin önsözünü oluşturmakta, filmin tonlamasını, havasını ve olayları önceden haber vermesiyle öncekilere göre farklılık yaratmıştır. Onun jenerikleriyle film gerçekten başlamaktadır (Scorsese, 1997).

Krasner'e (2008) göre; bir filmin açlış jeneriği izleyicilere verdiği ilk görüntü tecrübesidir. 1950'lerden beri film jenerikleri deneysel film yapımcılar tarafından ardışık evrimler geçirmiştir. Filmin açılışında jenerikler için kullanılan zaman, filmin içeriğini oluşturmak ve filmin atmosferi ve tonu hakkındaki beklentileri kurmak için kullanılmıştır. 1950'ler boyunca Saul Bass jeneriklerde fikir verici, mecazi görüntüleri kullanarak seyirciye film hakkında ipuçları vermiștir. Örneğin, 1959 yapımlı Bir Katilin Anatomis (Anatomy of a Murder) adlı filmde, koparılmış parçalardan oluşan bir silüeti tanıtmakta ve kareler Duke Elligton'un tematik müziği eşliğinde görüntülenmektedir. Ihanet duygusu ve her an olması beklenen felaket, izleyicileri koltuklarında tutmakta, başroldeki altın kollu adam, sivri kollu ve şifozrenik akıl yapısıyla önceden bir şeyin olacağını ima etmektedir (s.31). Jenerik'te kullanılan insan vücudu parçaları ve tipografi elle üretilmiş, bıçakla ya da makasla (cut-out) kesilmiş tarzda kullanılmış ve biçimle tipograf uyumludur. Tipografi, vücut parçalarını üzerinde, bazen bu parçaları yanında, grafik öğelerle bütünlük içerisinde kullanılmıştır (Görsel 3).

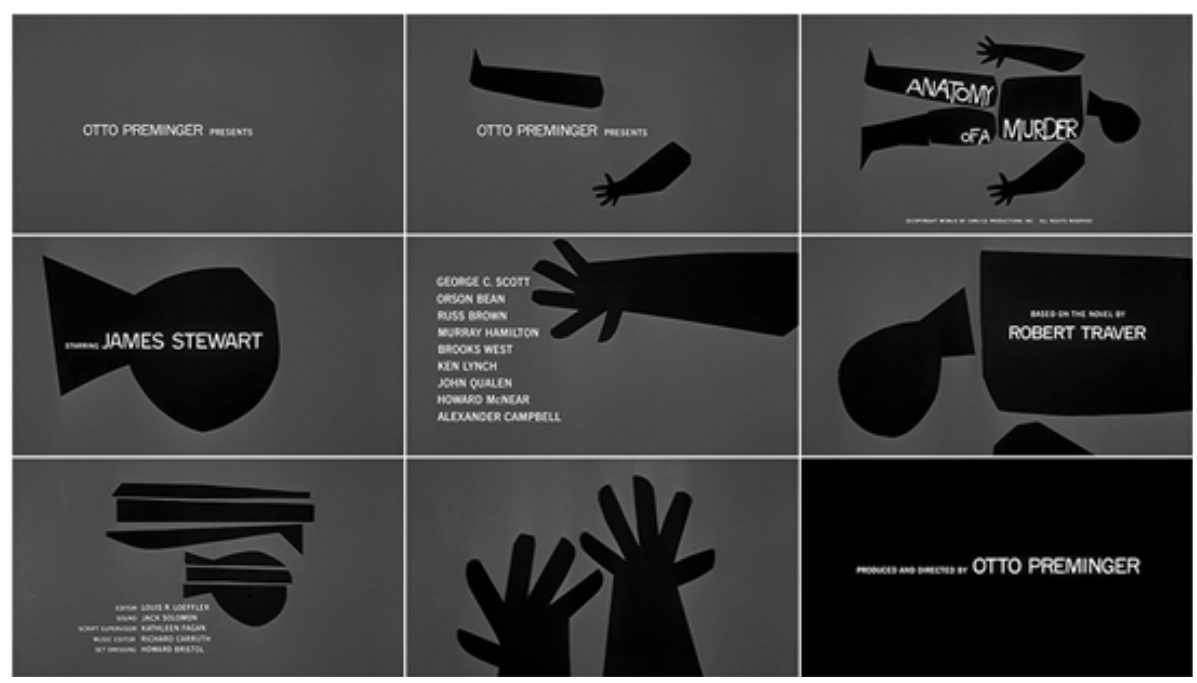

Görsel 3. Saul Bass, Anatomy of a Murder filmi açılış jeneriği, 1959, Video 
Saul Bass, Otto Preminger'in The Man with the Golden Arm (1955), Alfred Hitchcock'un Vertigo (1958), North By Northwest (1959) ve Psycho (1960), Stanley Kubrick'in Spartacus (1960), Bily Wilder The Seven Year Itch (1955), Martin Scorsese'nin Goodfellas (1990) ve Cape Fear (1991) gibi sinema tarihine damgasını vurmuş yönetmenler için film açıış jenerikleri tasarlanmış ve kamuoyunun büyük dikkatini çekmiştir.

Film jeneriklerindeki üç boyutlu hareketli tipografinin ilk örneklerine 20. yüzyılın yılların son çeyreğinde rastlanmaktadır. 1977 yılında, Richard Alan Greenberg ve kardeşi Robert tarafından kurulan "Greenberg Associates" şirketi Amerikan sinema tarihinde önemli klasiklerden biri olan 1978 yapımı "Superman" filmi için jenerik tasarımı hazırlamıștır. Krasner'e (2008: 23) göre hazırlanan jenerik tasarımı o dönem için bilgisayar destekli hareketli grafik kullanımı adına oldukça yenilikçidir. "Uçmak" fikrinden yola çıılarak hazırlanan jenerikte üç boyutlu hareketli tipografik ögelerle bilgisayar efektleri bir arada kullanılmıştır (Görsel 4).
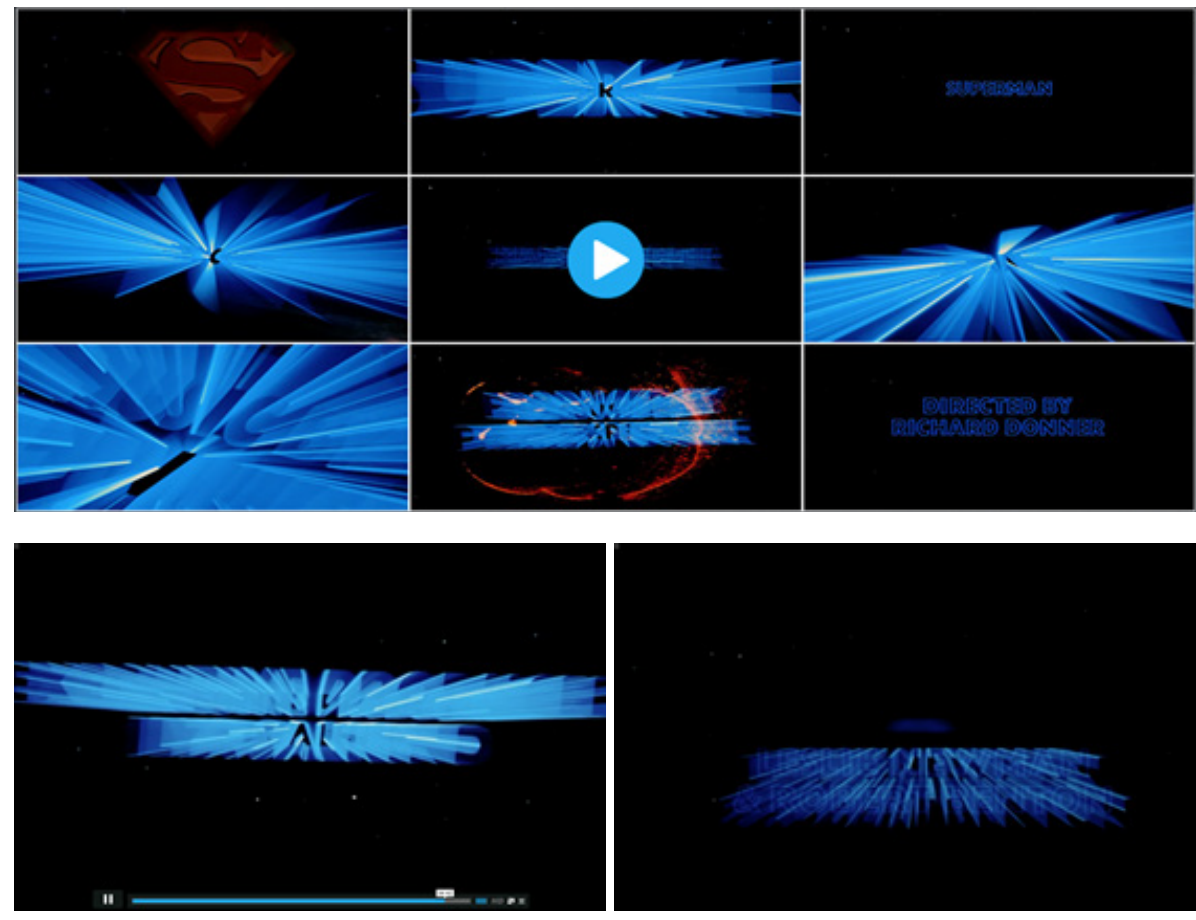

Görsel 4. Greenberg Associates, Superman" filmi açılış jeneriği, 1978, Video
David Fincher'ın yönetmenliğini yaptığı 2002 yapımı "Panic Room" filminin jeneriğinde üç boyutlu hareketli tipografi kullanılmıştır. Film jeneriğinde, New York sehrinin caddelerinde filmin konu olduğu mekanlarda kamera dolanırken, kentin binalarının önünde havada asılı büyük başlıklar, üç boyutlu yazılar görünmektedir. Tipografik ögeler şehrin mimarisi içinde, perspektifine ve ışı̆̆ına uygun, ama daha önemli ve önde gösterilmiştir (Görsel 5, 6). Computer Cafe film şirketinin görsel efekt uzmanı Akira Orikasa 'ya göre; "başlıklar, binalara yakın ama cephesine eklenmiş değil, önünde durması ve gerçek gibi görünmesi için inşa edildi. Işığı ve ögeleri birleştirme (kompoze etme) ışıklı sahnelerde, ışık parlamaları ile başlıkların çakışması önemlidir" (Braha ve Byrne, 2011: 22). Film jeneriğinde, inşa edildiği dönemin Arts\&Crafts, Art Nouveau ve Modernizm akımının etkilerini yansıtan mimari formlarla uyumlu tırnaklı bir font olan Copper Plate kullanılmıştır.
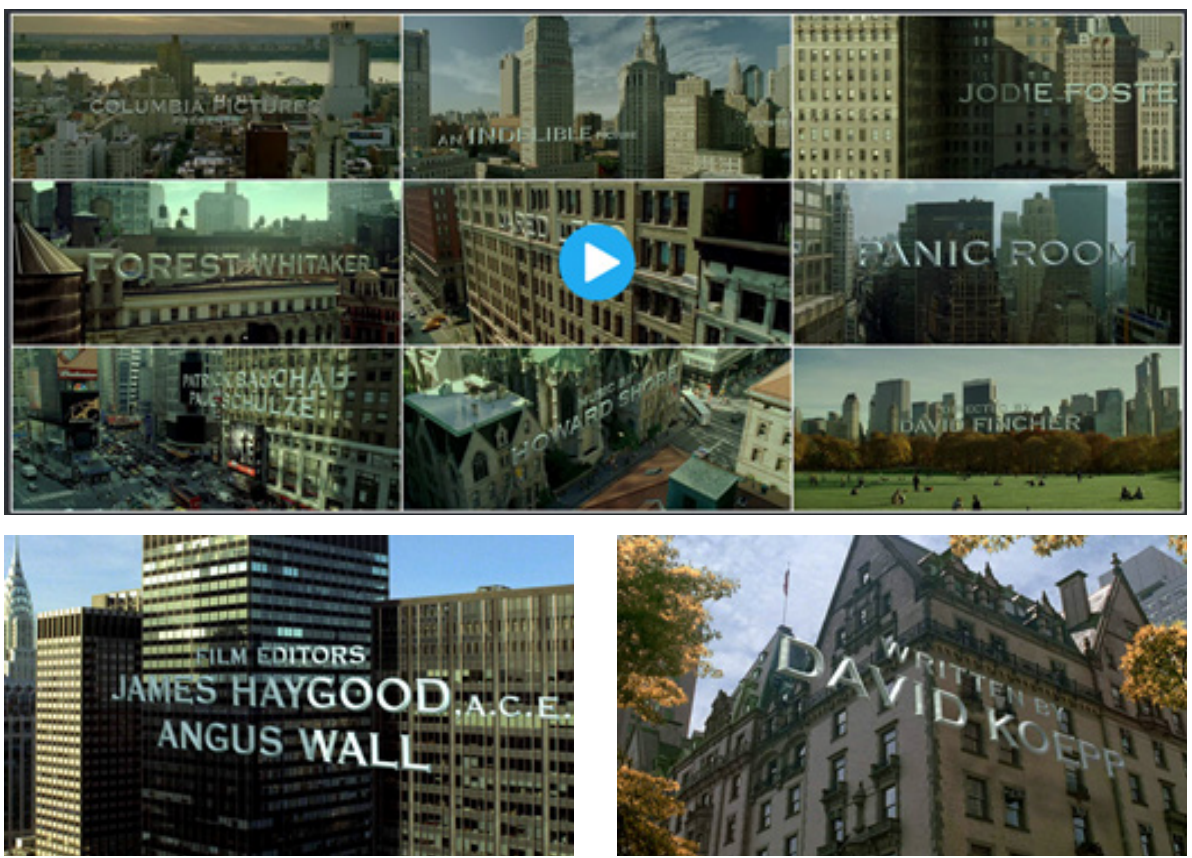

Görsel 5. Akira Orikasa, "Panic Room” filmi açılış jeneriği, 20I2, Video

Ortalama bir sinema izleyicisi için, filmin girişindeki krediler bölümü patlamış mısırlarını bitirmek için sadece üç dakikaları kaldığının göstergesidir. Ben bu ölü zamanı, film izleyicisinin ilgilenmediği isim listesini sunarak bu işten kurtulmanın ötesinde birşeyler için değerlendirmek istedim. İzleyiciyi izlemek üzere oldukları filme hazırlamak ve beklenti sahibi olmalarını sağlamayı hedefledim ("Bass on Titles", 2006). 


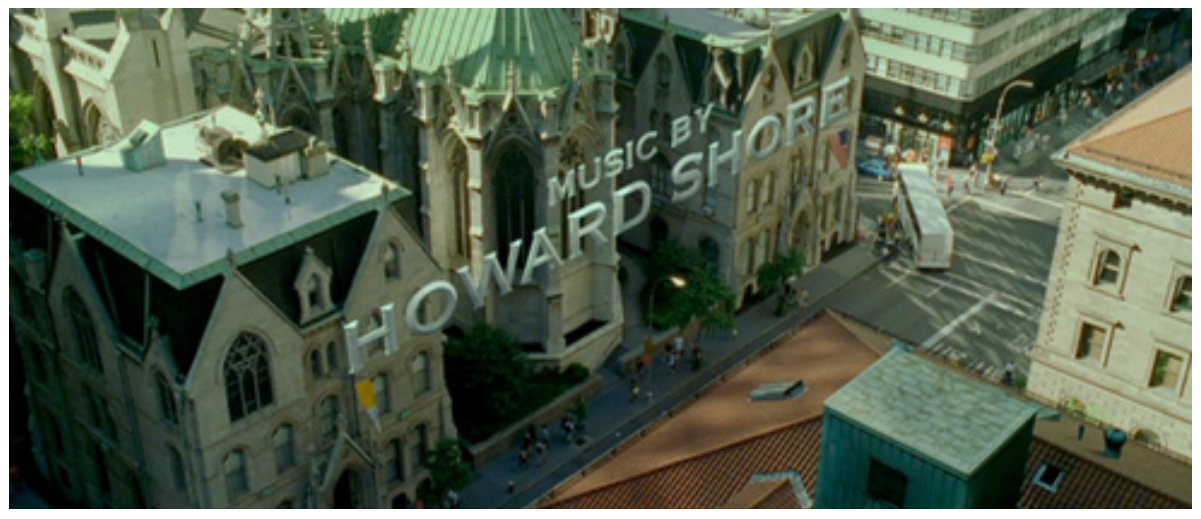

Görsel 6. Akira Orikasa, "Panic Room" filmi açılış jenerĭ̈i, 20I2, Video

Üç boyutlu hareketli ve kinetik tipografi kullanımına bir diğer örnek ise, yönetmenliği Ruben Fleischer tarafından yapılan 2009 yapımı "Zombieland" filmi için tasarlanan jeneriktir. Film jeneriği Logan firmasında Ben Conrad tarafından yapıımıştır. Jenerikte zombi saldırısından kaçmaya çalışan insanlar yakın çekim gösterilmektedir. Aynı zamanda bu karelerde üç boyutlu yazılar yer almaktadır. Üç boyutlu yazılar görüntülerdeki insan ve nesnelerle etkileşime girerek dağılmakta, kırılmakta veya bükülmektedir. Conrad "jenerikte, film ile tipografiyi birbirine entegre ederek masalsı bir anlatıma kavuşturmanın asıl amaçlarının olduğu... yavaşlatıımış görüntülerin yazı ile bütünlenmiş güzelliği, sahnelerdeki korku ve gerilimle kontrast oluşturduğunu belirtmektedir. Burada amaç yazının, dehşet verici duruma ve harekete tepki veriyor olmasıdır" Amaç değişmese de, jenerikte tipografi kullanımı ve görüntü kullanımı değiştirilmiş ve geliştirilmiştir (Görsel 7).

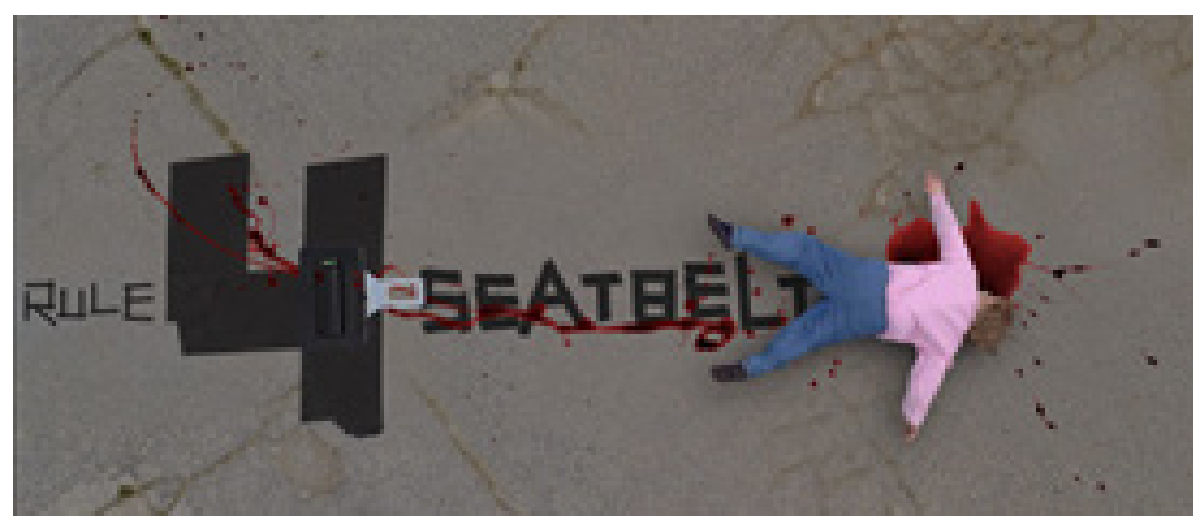

Görsel 7. Ben Conrad, Zombieland film jeneriği yayımlanmamıs taslakları, 2009, Video

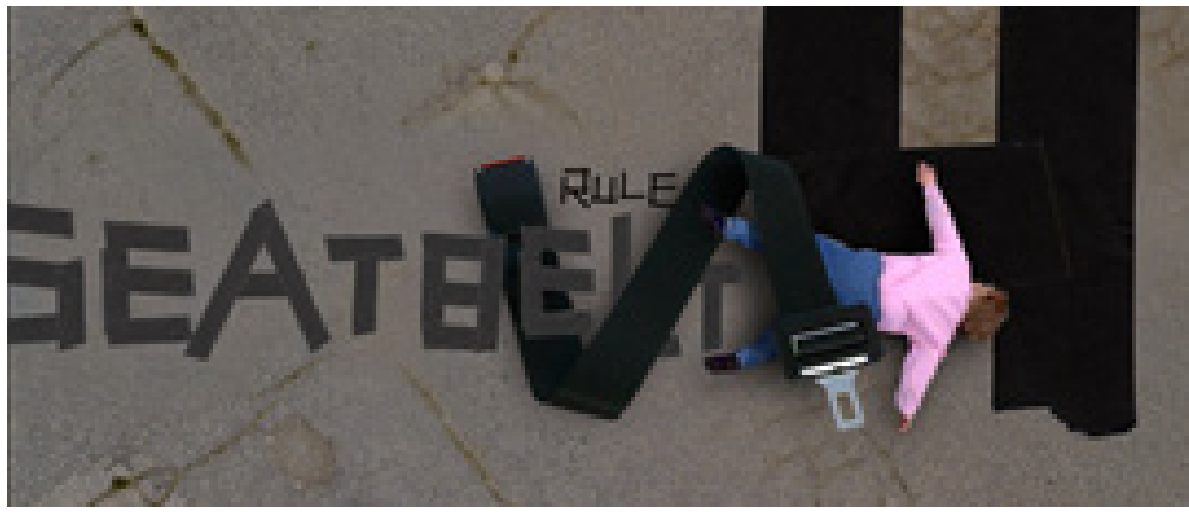

Görsel 7. Ben Conrad, Zombieland film jeneriği yayımlanmamış taslakları, 2009, Video
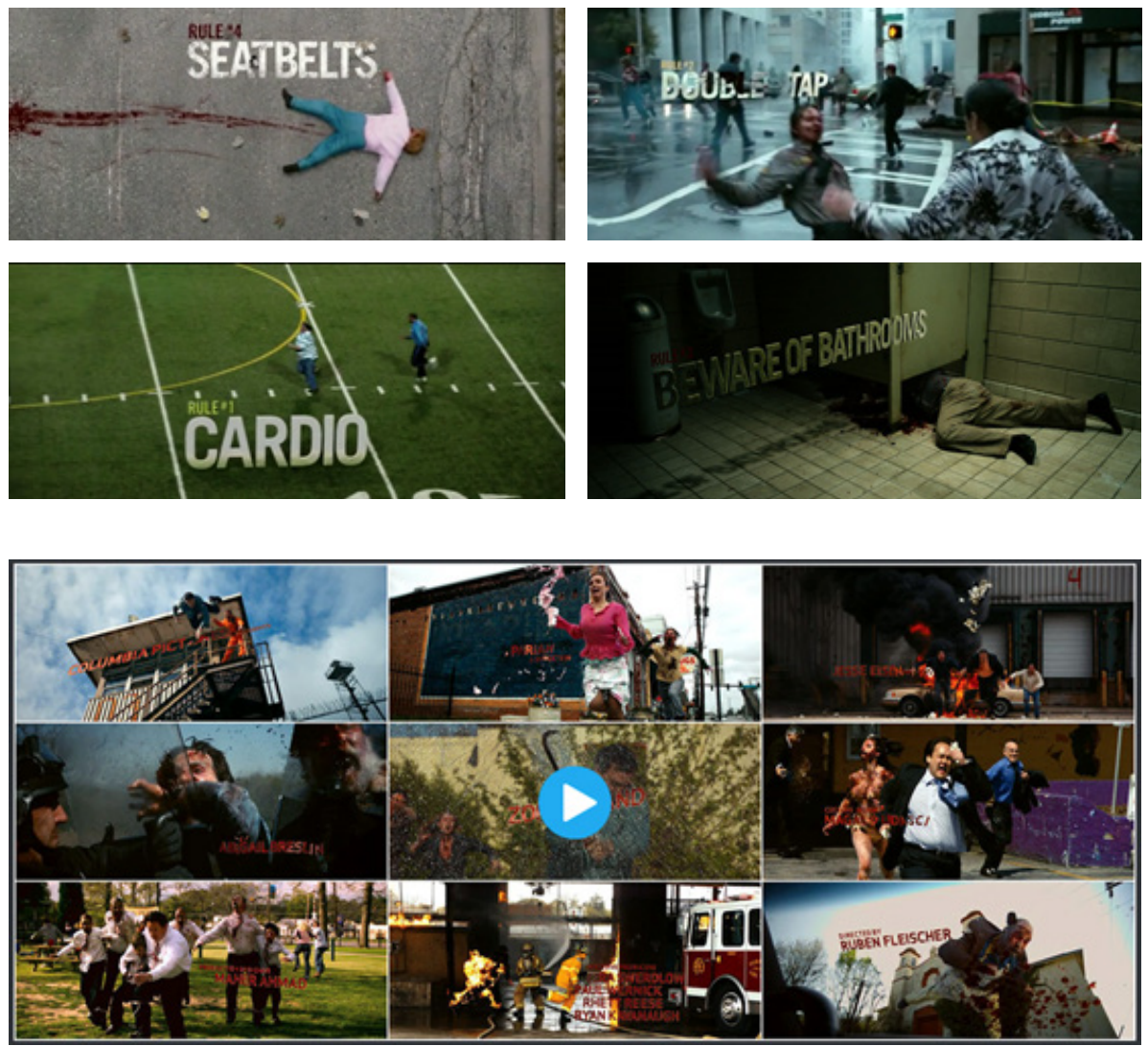

Görsel 8. Ben Conrad, Zombieland film jeneriği, 2009, Video 
Zombieland film jeneriğinde tipografi kullanımı yazının birincil amacı olan okutmaktan fazlasını ifade etmekte, görüntü ile tipografi uyum sağlamaktadır. Yazılar, sahnelerin görselliğine uygun tasarlanmıştır. Örneğin, "SEATBELTS" yazısı aynı görseldeki kan gibi bir etkiyi ifade ederken "CARDIO" yazısı kalp atışı gibi büyüyüp küçülmektedir. Böylelikle üç boyutlu tipografi, görüntüsü ve hareketi ile farklı duygu ve anlamları ifade etmektedir. Üç boyutlu kinetik tipografi için iyi bir örnek olduğu söylenebilir (Görsel 8).

\section{Televizyon}

Hareketli grafik, hareketli tipografi, kinetik tipografi ve üç boyutlu kinetik tipografi televizyonda yoğun olarak kullanımaktadır. Kanal logosu sunumu, televizyon yayıncilığı, reklamcilığı, programlar arası kurumsal jenerikler, haber, spor bültenleri gibi kurumsal program jenerikleri ve dizi jenerikleri bu alanlardan basslıcalarıdır. Yukarıda listelenen alanların birincil amac bilgi aktarmaktır. Bilginin aktarımı sürecinde görselliğin etkisi de oldukça önemlidir. Kinetik tipografi kullanımı ile bilginin aktarılması kolaylaşır, estetik ve çekici hale getirilebilir. Krasner'e (2008) göre erken dönem sinematik teknikler deneysel ve yenilikçi bir biçimde film jeneriklerine uygulanmıştır. Böylelikle televizyon, animasyon ve hareketli grafikler için yeni bir ortam olmuştur (s. 24). Bu yüzden bu alanlarda hareketli ve kinetik tipografi kullanımı yoğunluktadır.

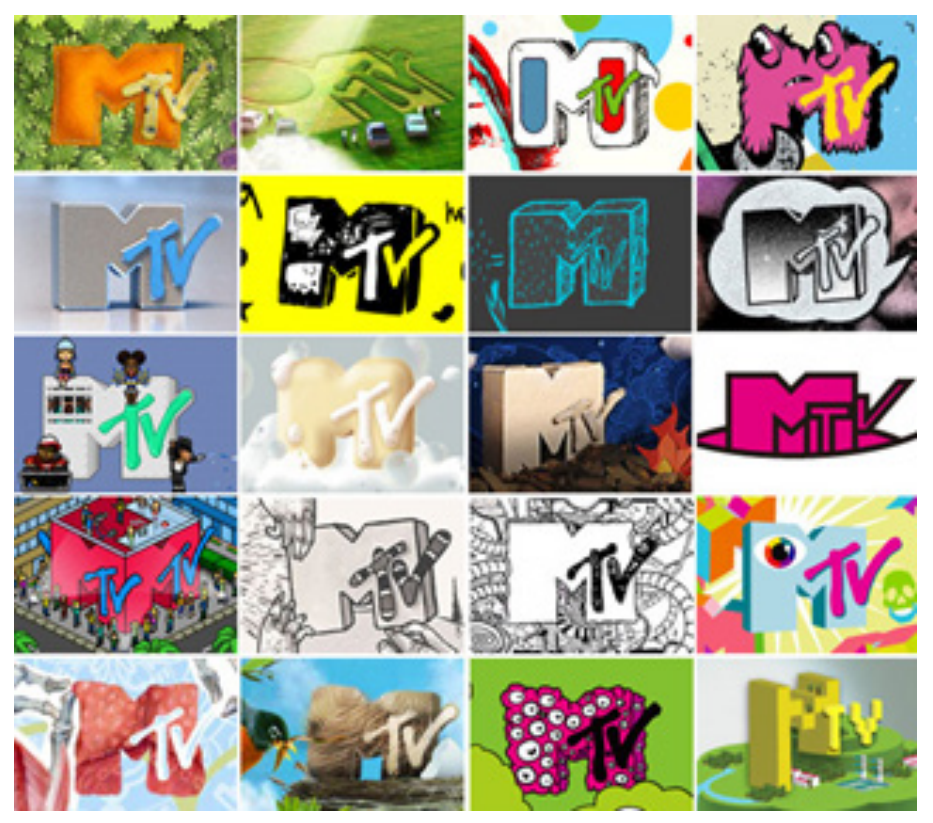

Görsel 9. MTV Logo yerleştirmeleri, Video
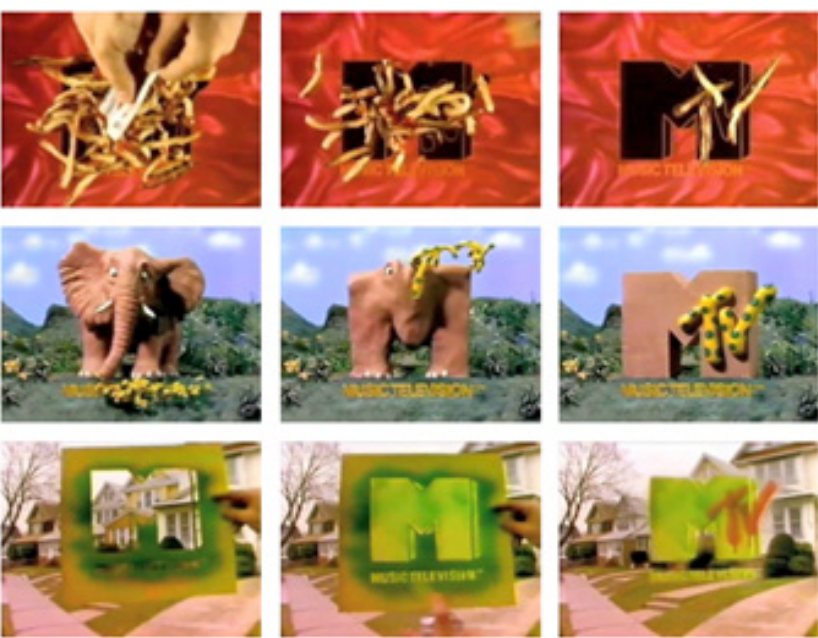

Görsel I0. MTV için kimlik çalışmaları, 198I-1983, Video

Üç boyutlu kinetik tipografinin önemli kullanım alanlarından olan logo sunumu için ünlü müzik kanalı MTV için yapılan tasarımların iyi örnekler olduğu söylenebilir. Kanalın müzik yayınları popüler, hareketli ve eğlenceli müzikler üzerinedir. Hedef kitlesi ve yayınları göz önüne alındığında deneysel logo çalışmalarında dinamik ve çarpıcı tasarımlar yapılmışıı (Görsel $9,10)$.

Logo; kalın, tırnaksız büyük " $M$ " harfi ve el yazısı biçimindeki " $T V$ " harfleri ile oluşturulmuştur. Farklı doku kullanımları ile oluşturulan tasarımlar çeşitli kültürlere ait yayın yaptığına vurgu yapmıştır (Görsel 9, 10).

2007 yapımı "How We Built Britain" belgeseli için Gareth Edwards'ın tasarladığı jenerik üç boyutlu hareketli tipografinin mekanla birleştirilerek kullanıldığı basarırı bir örnektir. Braha ve Byrne'a (2011) göre Gareth, kabu edilen konseptin dışında 8 farklı konsept üretmiştir. Britanya'nın manzaralarına oturttuğu harfleri binalar görünümünde tasarlar. Harfler binlerce yıllık İngiliz mimarisinin yapıları; Ortaçağ kaleleri, kiliseler, İskoç binaları, İngiliz kralları 1, 2, 3 ve 4. George dönemine ait evler (Georgian Houses), Viktorya binaları ve modern gökdelenler biçiminde gösterilmektedir. Gareth, hava çekimlerinden elde ettiği birçok görüntü arasından seçtiği mekanları kullanmışır (s. 18-19).

Belgeselin açוış jeneriği tasarlanırken, harf modelleri için 3D Studio Max programı, kaplamalar (textures) için Photoshop programı, mekanlar ve modellerin birleştirilmesi için After Effects programı ve izleme (tracking) işlemi için ise Boujou programı kullanılmıştır (Görsel 11). 

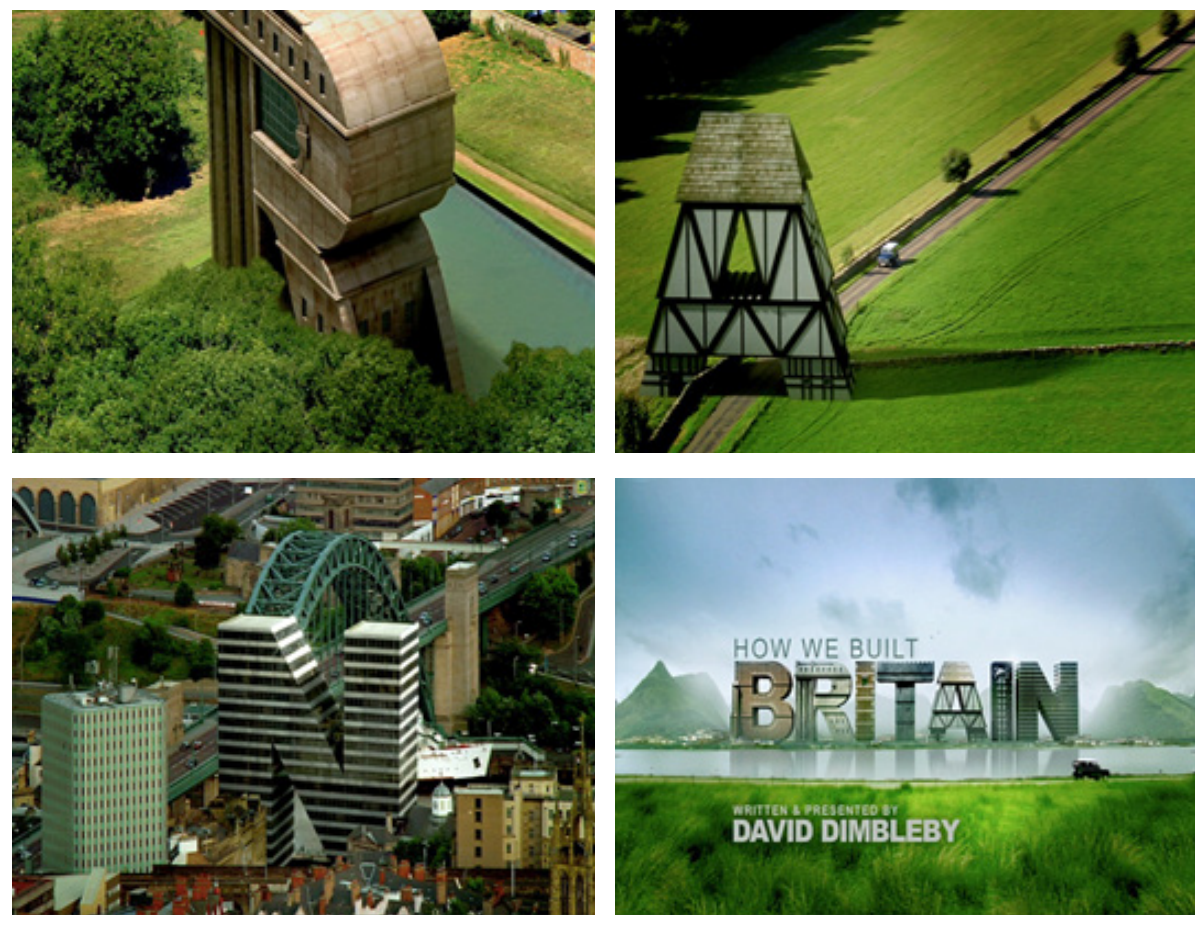

Görsel II. Gareth Edwards, "How We Built Britain" belgesel filmi açılış jeneriği, 2007, Video

BBC tarafından 1963 yılında çekilmeye başlanan Doctor Who adlı televizyon dizisi açılış jeneriklerinde kullandığı yaratıcı çözümler ile önemli bir başka örnektir.

Dizi; doktor olarak bilinen, zamanda yolculuk yapan, insansı, dünya dışı yaratık olan Zaman Lordu'nun maceralarını anlatmaktadır. Doktor, dışarıdan 1950'lerden kalma bir polis kulübesi gibi görünen TARDIS adındaki bilince sahip ve zamanda yolculuk edebilen bir uzay gemisi ile evreni araştıır. Doktor, yol arkadașları ile beraber uzay ve zamanı keşfeder, sorunları çözer, yaratıklarla yüzleşir ve tarihe yapılan müdahalelere engel olur. ${ }^{1}$

Guinness Rekorlar Kitabı tarafından dünyanın en uzun süren bilim kurgu televizyon programı olarak listelenen dizi 1990'lardan itibaren 10 senelik bir aradan sonra, 2005'te daha modern ve yeni bir seriyle çekilmeye başlanmıştır.

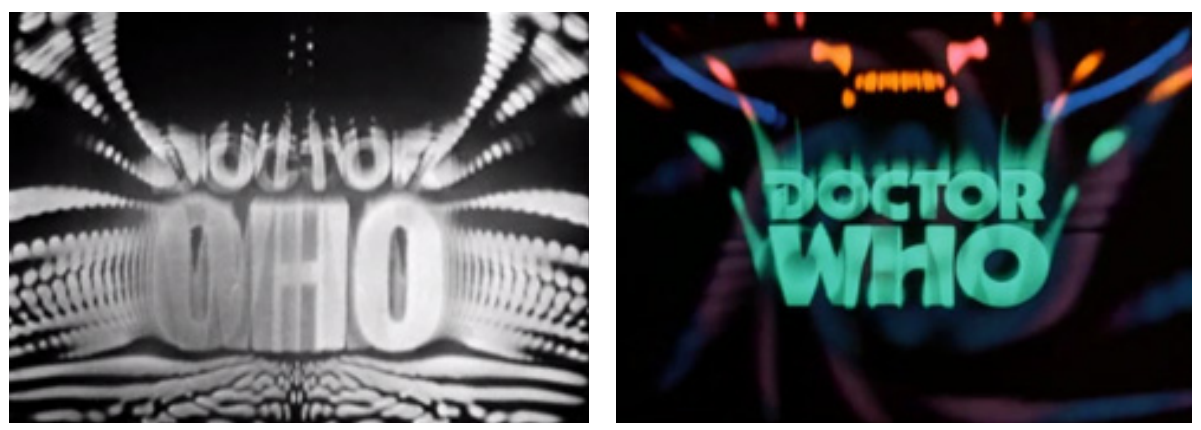

Görsel I2. Bernard Lodge, Doctor Who Açılış Jeneriği, 1963 Video Jon Pertwee, Doctor Who Açllış Jeneriği, 1970 Video

Dizinin ilk yıllarındaki açılış jenerikleri incelendiğinde yazıların hareketlendirilme ve görüntü ile birleştirilme çabaları dikkat çekmektedir. Ilk jenerik Bernard Lodge tarafından yapılmış ve siyah beyazdır. Jon Pertwee 1970 yılında yaptığı jeneriği renklendirmiş ve logosunu değiştirmiştir (Görsel 12). Günümüze doğru dizinin jenerikleri de değişmekte, üç boyutlu hareketli tipografi daha fazla kullanılmaktadır (Görsel 13, 14).
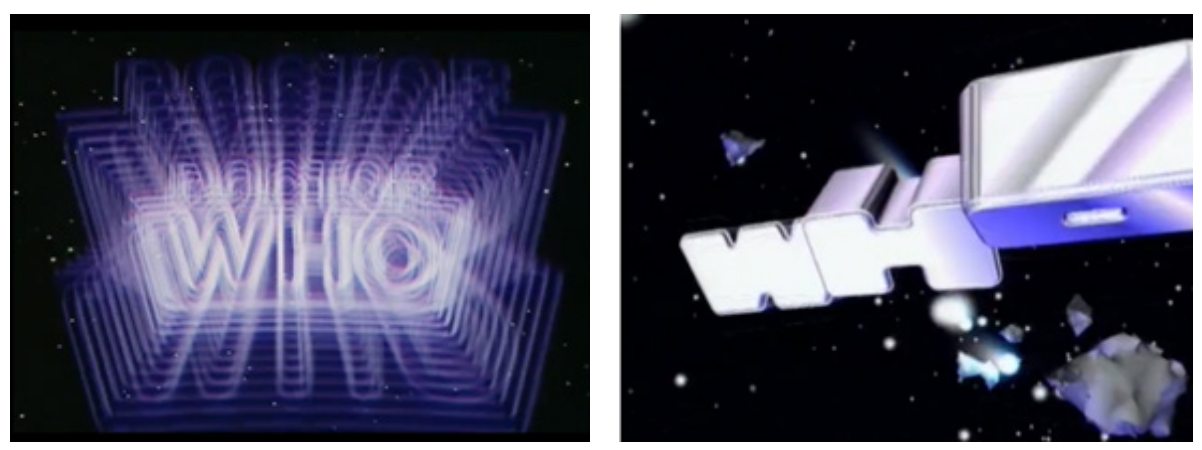

Görsel 13. Cal Video, Doctor Who Açllş Jenerikleri, 1984-1987, Video

1987 yılında yapılan jenerik CGI (Computer Generated Imagery) bilgisayar grafikleri ile yapılmıştır. Logosu Oliver Elmes, jenerik Cal Video firması tarafından yapılmıştır.

' Internet: www.hurriyet.com.tr/doctor-who-neden-googlea-doodle-oldu-25/81072 adresinden 14 Ekim 2017'de alınmıștır. 

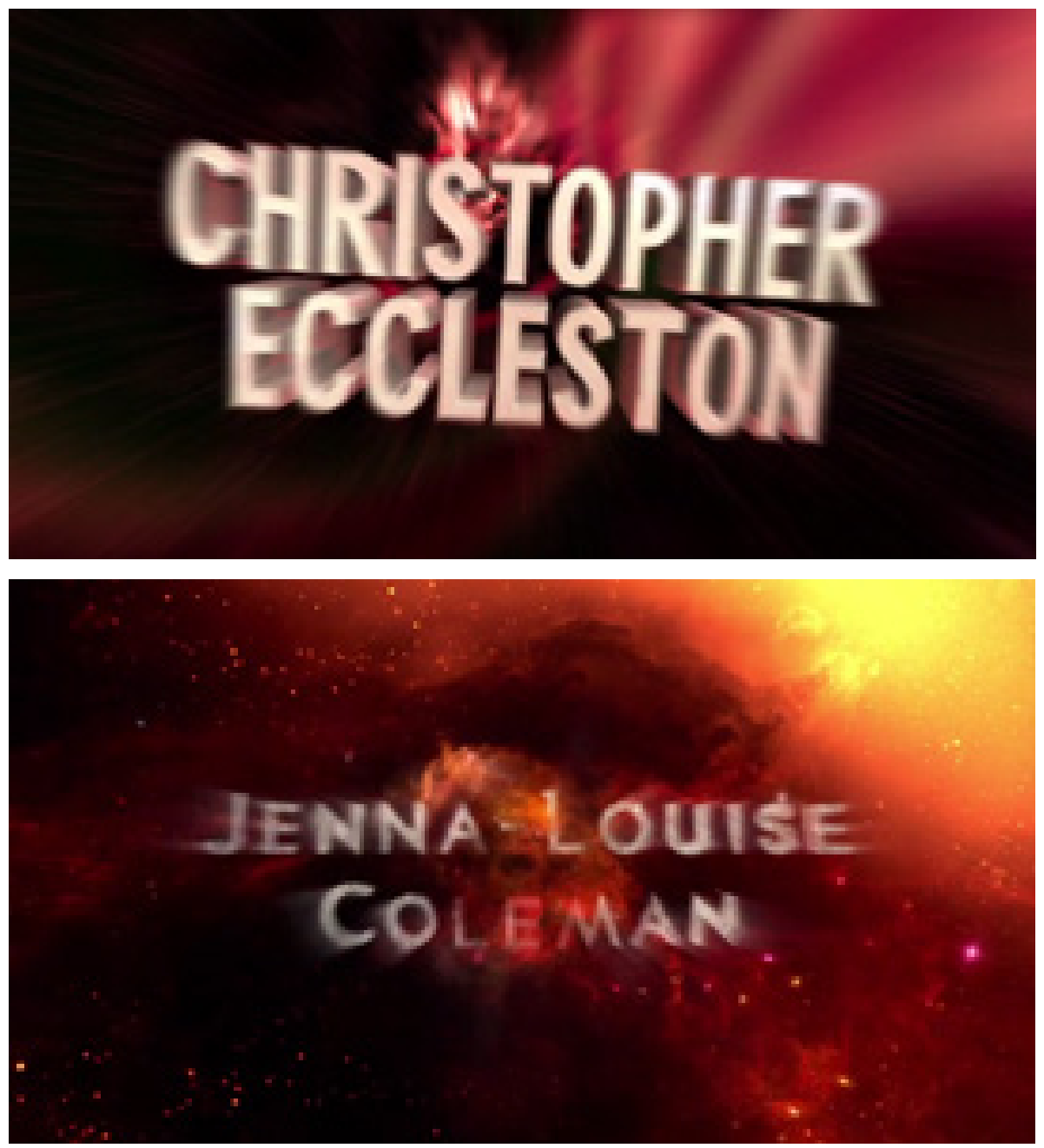

Görsel I4. Phil Collinson, Doctor Who Açוlıs Jenerikleri, 2005-20I2, Video

9 yıl aradan sonra 2005 yılında $B B C^{\prime}$ ye geri dönen dizinin logosu ve jenerikleri Phil Collinson ve ekibi tarafından yeniden ele alınmıştır. Bu kadar ara verilmesine karşın dizi yeni çekimleri ile büyük bir izlenme kitlesine ulaşmı̧ ve dizi yeni bölümleriyle yayınlanmaya devam etmektedir.

\section{Sayısal Ortamlar}

Üç boyutlu kinetik tipografi kullanımına, bilgisayar oyunlarında ve tanıtımlarında, kurumsal logo ve proje sunumlarında, etkileşimli CD'lerde, müzik videolarında rastlanmaktadır.
Tom Clancy's The Division oyununun açılış videosunda üç boyutlu kinetik tipografi, özellikle oyunun konusu anlatılırken yoğun olarak kullanılmışıı (Görsel 15, 16). 2015'te piyasaya sürülen oyun, para üzerinden bulaşan bir virüs nedeniyle çöken toplumsal yaşantıyı konu almaktadır. Oyuncular, ABD hükümetinin The Division adlı gizli organizasyonunun üyesi olan bir ajanı kontrol edecekler ve bir yandan virüsün sebebini araştıırken bir yandan da şehirdeki diğer gruplarla savaşacaktır.
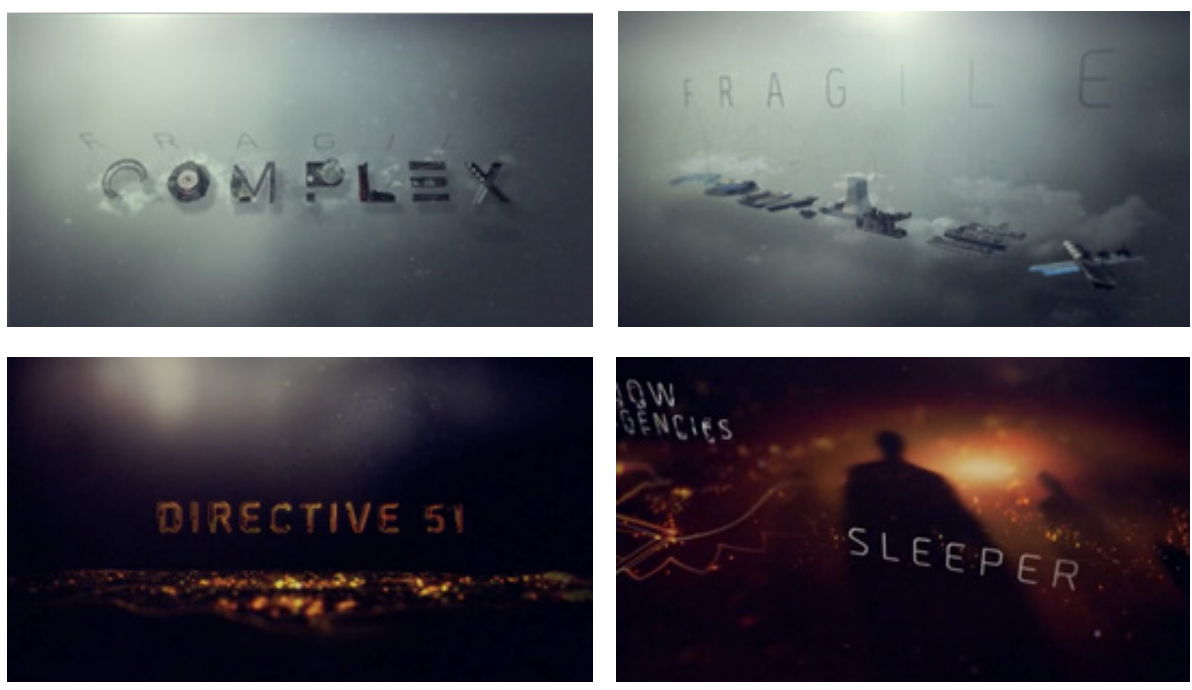

Görsel I5. Tom Clancy's The Division tanıtım filminden görüntüler

Tanıtım filminde "complex" kelimesini oluşturan harfler her biri kendi içinde ayrı bir kavramı anlatan mekan gibi kullanılmıştır. Örneğin X harfi petrol ve türevlerinin çıkarıldığı ve işlendiği bir rafineri gibi, $C$ harfi ise ulaşımı anlatmak için üzerinde otomobil ve tırların yol aldığı otobanlar seklinde tasarlanmışıtır. $M$ harfine havaalanı görselleri ile hava taşımacılı̆̆ı kavramı yüklenirken; P harfine enerji sektörünü anlatmak için power (güç) kelimesi ile özdeşleştirilerek, fabrika bacaları çizimleri ile çözümlenmiştir (Görsel 16)

Virüsün etkisini göstermesinin ikinci gününde ulaşım kilitlenir. $C$ harfi yol şeklinde tasarlanmıştır. Filmin başında bu harf üzerinde akan bir ulaşımı görülmekteyken filmin sonlarına doğru virüsün etkisi ile ulaşım kilitlenmektedir. Bu etki yine aynı harf üzerinden anlatılmaktadır. Üçüncü günde uluslararası ticaret durur. E harfi üzerinde gösterilen gemi taşımacılığı (shipping) filmin sonlarına doğru feribotların üzerinde olan konteynerların devrilmesi ile uluslararası ticaretin durduğu ifade edilmektedir (Görsel 17). 

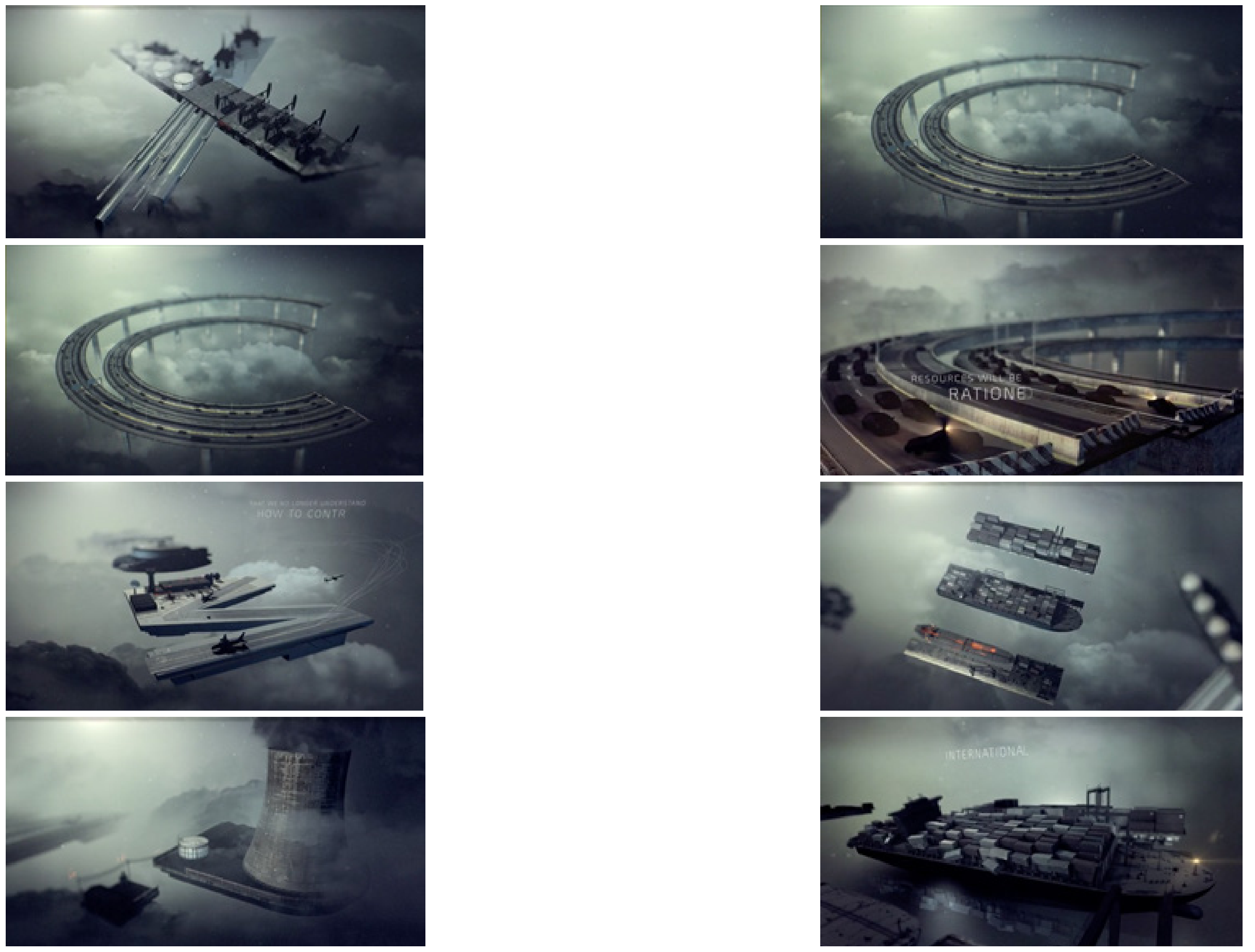

Görsel 16. Tom Clancy's The Division tanıtım filminden görüntüler

Görsel 17. Tom Clancy's The Division tanıtım filminden görüntüler 
Bu çalışmada tipografi, okunmanın ötesinde ikincil anlatımı olarak imgeyi vurgulamaktadır. Kavramlar, durumlar ve olgular harfler üzerinden anlatılmıştır. Görsel olarak zengin bir anlatıma sahip olan çalışma ayn zamanda izleyiciye çok daha hızlı ulaşmaktadır. Bu anlatım sayesinde etki güçlendirilmiştir. Üç boyutlu kinetik tipografi için iyi bir örnek olduğu söylenebilir

\section{Sonuç}

Kinetik tipografi uygulamalarının film açılış jeneriklerinde ilk örnekleri 1950'lerde görülürken, masaüstü yayıncılığın 1985'lerden itibaren gelişimi ve 1990 'larda çoklu ortam uygulamalarının yaygınlaşması sayesinde video kliplerde ve web içeriklerinde de kinetik tipografi uygulamaları görülmeye başlanmıştır. Teknolojiler özellikle bilgisayar teknolojileri, tipografinin her geçen gün gelişmesinde, değişmesinde ve farklılaşmasında yeni olanaklar sunmaktadır. Gelişen yazılım ve donanımlar üç boyutlu çalışmaların daha kolay yapılmasına yol açmışır. Hareketlendirme ve üç boyutlu yazılımların geliştirilmesi sayesinde kinetik tipografi ve üç boyutlu kinetik tipografi uygulamaları sinema, televizyon, çoklu ortam (multimedia), vb. ortamlarda daha sık kullanılır hale gelmiştir.

Üç boyutlu kinetik tipografi kavramı üzerinden, kullanım alanlarının incelendiği bu araştırma üç boyutlu kinetik tipografi tasarımının günümüz dijital dünyasında sürekli gelişen bir yapıya sahip olduğunu ortaya koymuştur. Bu yapının ise tipografik unsurlar çerçevesinde daha etkili daha donanımlıtasarımların ortaya çıkarılmasına katkısı olduğu görülmüştür.

Sayısal ortamda üç boyutlu kinetik tipografinin gerçekleştirilmesi tasarıma bağlı olarak; öykü panosu, modelleme, kaplama, ışıklandırma, animasyon, render, ses tasarımı ve kurgudan oluşan bir dizi aşamaları gerektirebilir Öyle ki, bu aşamaların hepsi ayrı birer uzmanlık alanıdır ve çoğunlukla multidisipliner bir çalışma gerektirmektedir. Teknoloijinin sunduğu olanaklar ile sayısal ortamda tasarlanan tipografik çalışmalar yeni ifade olasılıklarını izleyiciye sunmaktadır. 


\section{Kaynakça}

Bass, S. (Yönetmen). (1977). Bass on Titles. (DVD) Santa Monica, CA: Pyramid Media.

Bodnie, K., Pignol, M. (2003). Kinetic Typography - Based Instant Messaging. CHI 2003 New Horizons. Florida: Fort Lauderdale.

Braha, Y., Byrne, B. (20II). Creative Motion Graphic Titling For Film, Video, And The Web. Oxford: Focal Press.

Kılıç, E. (20II). Kinetik Tipografi: Bir Müzik Videosu Tasarımı, Yayımlanmamış Sanatta Yeterlik Tezi, Hacettepe Üniversitesi Sosyal Bilimler Enstitüsü, Ankara.

Krasner, J. (2008). Motion Graphic Design Applied History and Aesthetics. Oxford: Focal Press.

Sarıkavak, N.K. (20/3). "iletişimde Tasarım - Tasarımda Iletişim için Modernitenin Çözümü: Kavramsal Tipografi”, L. Mercin (Ed.). Iletişimde Tasarım - Tasarımda Iletişim

Uluslararası Sempozyumu (ss. 23-37). Kütahya

Scorsese, M. (1997). Saul Bass as a Designer of Films. 6 Chapters in Design. San Francisco: Chronicle Books.

\section{Görsel Kaynakları}

Görsel I: Hareketli Tipografi'ye bir örnek, 20I7, Video. www.youtube.com/ watch? $v=w T s 8 Z W L Q 49 M$ adresinden 14 Ekim 20I7'de alınmıştır.

Görsel 2: Alex Gopher, The Child Kinetik Tipografi'ye bir örnek, 2007, Video. https:// vimeo.com/95605794 adresinden I4 Ekim 2017'de alınmıştır

Görsel 3: Saul Bass, Anatomy of a Murder filmi açılış jeneriği, 1959, Video

www.artofthetitle.com/title/anatomy-of-a-murder adresinden I4 Ekim 2017'de alınmıștır

Görsel 4: Greenberg Associates, Superman” filmi açılış jeneriği, 1978, Video

www.artofthetitle.com/title/superman adresinden I 4 Ekim 2017'de alınmıştır.

Görsel 5-6: Akira Orikasa, "Panic Room" filmi açılış jeneriği, 2012, Video www. artofthetitle.com/title/panic-room adresinden 14 Ekim 2017'de alınmıştır.

Görsel 7: Ben Conrad, Zombieland film jeneriği yayımlanmamış taslakları, 2009, Video

www.artofthetitle.com/title/zombieland adresinden I 4 Ekim 2017'de alınmıştır.
Görsel 8: Ben Conrad, Zombieland film jeneriği, 2009, Video

www.artofthetitle.com/title/zombieland adresinden I 4 Ekim 20I7'de alınmıştır.

Görsel 9: Mtv Logo yerleştirmeleri, Video. https://tr.pinterest.com/ pin/430797520577I53539 adresinden I4 Ekim 20 I7'de alınmıştır.

Görsel I0: MTV için kimlik çalışmaları, 1981-1983, Video.

https://www.youtube.com/watch?v=2zkKvJ67omU adresinden 14 Ekim 2017'de alınmıştır.

Görsel I I: Gareth Edwards, "How We Built Britain” belgesel filmi açılış jeneriği, 2007, Video. www.artofthetitle.com/title/how-we-built-britain adresinden I4 Ekim 2017'de alınmıştır.

Görsel I2: Bernard Lodge, Doctor Who Açllış Jeneriği, 1963 Video.

Jon Pertwee, Doctor Who Açılış Jeneriği, 1970 Video.

www.artofthetitle.com/feature/doctor-who-50-years-of-main-title-design adresinden 14 Ekim 2017'de alınmıştır.

Görsel 13: Cal Video, Doctor Who Açוlış Jenerikleri, 1984-1987, Video

(www.artofthetitle.com/feature/doctor-who-50-years-of-main-title-design)

14 Ekim 20I7'de alınmıştır.

Görsel I4: Phil Collinson, Doctor Who Açılış Jenerikleri, 2005-20I2, Video www. artofthetitle.com/feature/doctor-who-50-years-of-main-title-design adresinden 14 Ekim 2017 'de alınmıştır.

Görsel I5-16-17:Tom Clancy's The Division tanıtım filminden görüntüler vimeo.com/682I5272 adresinden I4 Ekim 2017'de alınmıştır.

\section{Internet Kaynakları}

Internet: Bachfischer, G., Robertson, T., Zmijewska, A. (2007). Typography in Motion: A framework of Moving Type Use. WSEAS Transaction on Information Science and Applications, Vol. 3 Web: epress.lib.uts.edu.au/research/bitstream/handle//0453/5748/2006005294. pdf?sequence $=$ I adresinden 09 Haziran 2013'de alınmıştır.

www.artofthetitle.com/title/zombieland adresinden I4 Ekim 2017'de alınmıștır. 
www.artofthetitle.com/feature/doctor-who-50-years-of-main-title-design adresinden 14 Ekim 2017'de alınmıştır.

www.hurriyet.com.tr/doctor-who-neden-googlea-doodle-oldu-25/81072 adresinden 14 Ekim 2017'de alınmiştır. 